\title{
Anne-Laure Zwilling (dir.), Minorités religieuses, religions minoritaires dans l'espace public. Visibilité et reconnaissance
}

Strasbourg, Presses universitaires de Strasbourg, coll. « Société, droit et religion ", 2014, $250 \mathrm{p}$.

Régis Dericquebourg

\section{OpenEdition}

\section{Journals}

Édition électronique

URL : http://journals.openedition.org/assr/27495

DOI : 10.4000 /assr.27495

ISSN : $1777-5825$

Éditeur

Éditions de l'EHESS

Édition imprimée

Date de publication : 1 octobre 2015

Pagination : 391

ISBN : 978-2-7132-2515-4

ISSN : 0335-5985

\section{Référence électronique}

Régis Dericquebourg, «Anne-Laure Zwilling (dir.), Minorités religieuses, religions minoritaires dans

l'espace public. Visibilité et reconnaissance ", Archives de sciences sociales des religions [En ligne], 172 | octobre-décembre, mis en ligne le 22 juin 2016, consulté le 24 septembre 2020. URL : http://

journals.openedition.org/assr/27495; DOI : https://doi.org/10.4000/assr.27495

Ce document a été généré automatiquement le 24 septembre 2020.

(C) Archives de sciences sociales des religions 


\section{Anne-Laure Zwilling (dir.), Minorités religieuses, religions minoritaires dans l'espace public. Visibilité et reconnaissance}

Strasbourg, Presses universitaires de Strasbourg, coll. « Société, droit et religion $», 2014,250 \mathrm{p}$.

Régis Dericquebourg

\section{RÉFÉRENCE}

Anne-Laure Zwilling (dir.), Minorités religieuses, religions minoritaires dans l'espace public. Visibilité et reconnaissance, Strasbourg, Presses universitaires de Strasbourg, coll. « Société, droit et religion », 2014, 250 p. 
1 Ce livre présente le bilan d'une recherche sur la diversité religieuse en Europe menée dans treize universités qui a été financée par la Commission européenne. Il a l'intérêt de traiter des minorités religieuses tels les Témoins de Jéhovah, qui ne font pas partie des Églises minoritaires reconnues, comme des éléments incontestables du paysage religieux européen, le judaïsme, l'islam, le protestantisme et le catholicisme orthodoxe.

2 L'ouvrage comporte trois parties: 1) la constitution des frontières de la minorité et l'élaboration des cadres juridiques de la reconnaissance des minorités; 2) État, institutionnalisation, encadrement ; 3) Visibilité et stratégies de visibilisation.

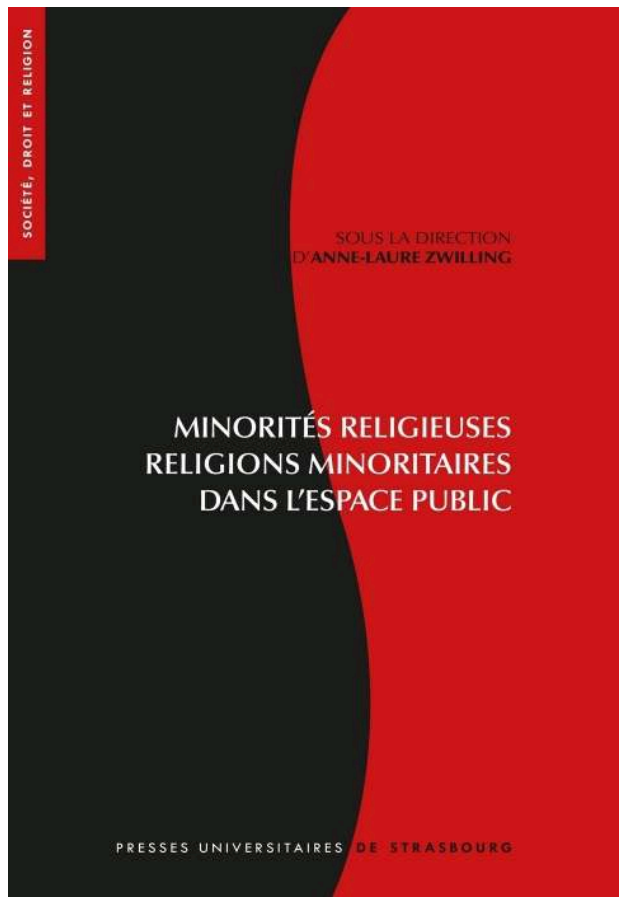
La première partie rejoint une réflexion qui est exposée dans Pluralisme et minorités religieuses (J. Baubérot, éd., Louvain, Peters, 1991) où l'on admet que la minorité ne se définit pas seulement objectivement par la statistique, mais qu'elle se définit aussi par la subjectivité des minoritaires et, statutairement, par un type de relation avec la société globale qualifiée ici d'espace public. La première partie rejoint aussi les considérations sur la protection juridique et la délégitimisation des groupes religieux minoritaires exposées dans de nombreux colloques, dont les actes furent publiés chez L'Harmattan et auxquels participaient Émile Poulat, Alain Garay, Olivier Séguy, Massimo Introvigne, Gérard Ducrey, Dominique Kounkou et Régis Dericquebourg (Un bilan de la liberté religieuse en France, 2001; Les Nouvelles formes du sentiment religieux, 2003 ; Les discriminations religieuses, 2004). La délégitimisation concerne principalement les minorités que l'on a qualifiées de "secte " au sens péjoratif, Nicolas Guillet en énumère quelques-unes. Il omet un argument de cette délégitimisation, soutenu par des opposants aux sectes des catholiques romains et des catholiques orthodoxes : le déni du caractère religieux. Les « sectes » ne seraient pas de la religion. Les associations qui regroupent ce courant antisecte répètent que les Témoins de Jéhovah, les Scientologues, le Mandarom ne sont pas de la religion. Les auteurs ne relèvent pas non plus une contradiction qui vient de certaines associations de Droits de l'Homme d'obédience rationaliste, lesquelles peuvent défendre des minorités religieuses au nom de leurs principes et qui en condamnent d'autres, comme les Témoins de Jéhovah, sous prétexte que « les sectes ne respectent pas les droits de l'homme » comme nous l'avons lu parfois. Hocine Sadok montre que face à cette délégitimation, le recours aux tribunaux devient une stratégie d'affirmation du caractère religieux de ces sectes. Il rejoint ici ce que nous avions montré dans «Les stratégies des groupes religieux minoritaires face à la lutte antisecte en France" (Religiologiques, 22, automne 2000, p. 119-130). La première partie de l'ouvrage évoque aussi le rôle des femmes dans les religions (Lucie Veyretout). Il s'agit moins d'une minorité que d'une minorisation, car les femmes peuvent être statistiquement majoritaires dans une religion tout en étant 
maintenues dans un statut secondaire. La neutralité de l'État interdit à celui-ci de se mêler de la répartition des rôles socioreligieux d'un culte en fonction du genre, mais il peut, par le biais de considérations d'ordre public, intervenir sur des pratiques censée liées à la religion, comme le port de la burqa. Dans une recherche sur le Droit des religions, une place doit être attribuée à la notion d'ordre public qui constitue, dans la loi de 1905, la limite de la liberté religieuse. Elle n'y est pas définie et elle ne peut donc l'être que par les jugements, cas par cas, faisant jurisprudence. Stéphane Ollion analyse l'ostracisation des Témoins de Jéhovah opérée en France sous la houlette des associations antisectes. Pour l'auteur, ces dernières ont construit les Témoins de Jéhovah comme secte au sens péjoratif et non au sens webero-troeltschien neutre, comme l'ont fait les sociologues qui ont écrit sur eux (Wilson, Beckford, Dericquebourg). Il constate un changement dans le vocabulaire de l'ADFI (association pour la Défense des Familles d'Individus victimes de sectes) qu'il attribue au changement d'orientation même de cette association. Quand elle était d'obédience catholique, l'ADFI ne se préoccupait pas du jéhovisme, pour éviter de voir les critiques qui lui étaient adressées se retourner contre le catholicisme. Ayant fait notre thèse sur les Témoins de Jéhovah et ayant observé les opposants aux sectes, nous pensons qu'il y a effectivement eu un changement d'attitude vis-à-vis des Témoins mais pour d'autres motifs. Toutefois, il est juste de montrer les variations dans la lutte contre les dites sectes. L'argumentaire des opposants aux sectes a épousé les idées, les peurs et les combats à la mode. Ainsi on a pu entendre dire que « les » sectes sont d'extrême-droite, quand les médias et les politiques évoquaient une "montée de l'extrême-droite ». Puis leurs détracteurs ont dit que les sectes ne respectaient pas les femmes. Elles ont aussi été qualifiées de "cheval de Troie de l'Amérique", idée déjà développée sous le nazisme à propos des Témoins de Jéhovah (assimilés à un prétendu «judéomaçonnisme » américain).

3 La seconde partie porte sur les tentatives de régulation de l'islam par l'État français au niveau du culte, des pratiques et de l'organisation pour promouvoir un «islam à la française » (Solenne Jouanneau) à mesure que les musulmans devenaient visibles dans la société française et affirmaient un mode de vie en relation avec leurs croyance. L'auteur en indique les modalités : surveillance de l'entrée des imams en France, action sur la formation de ces derniers, tentatives pour favoriser la constitution d'organismes représentatifs contrôlables. On peut y voir une minorisation de l'islam au sens où celuici devrait nécessairement être sous tutelle. Dès lors, des musulmans auraient mis en place des stratégies en vue de se rendre visibles (Simona Tersigni) dans la société. En réaction, les signes visibles et publics ont alimenté un débat sur la laïcité. Cet article fait la transition avec la troisième partie qui contient des études de terrain sur les modes de «visibilisation» de minorités religieuses. Jean Schmitz montre que les musulmans de l'Afrique de l'Ouest à la fois minorisés comme musulmans à Paris et discriminés parmi les musulmans (parce qu'ils sont associés à l'esclavage), devenus une "minorité dans la minorité musulmane ", répondent à cette condition en suivant la voie de la connaissance et du quiétisme dans l'islam. Il est donc intéressant d'apprendre comment une situation sociale oriente le choix d'une spiritualité, comme le montre Max Weber au début de sa sociologie de la religion. Christine Moliner rappelle le combat identitaire des Sikhs en Grande-Bretagne où la revendication du port du turban dans la vie quotidienne a été acceptée sur la base de considérations historiques. En effet, les sikhs ont combattu en turban aux côtés des soldats anglais pendant les deux guerres mondiales. S'ils ont pu risquer leur vie en turban pour l'Empire britannique, 
pourquoi ne pourraient-ils pas conduire un autobus avec ce signe religieux? La question du turban avait été préalablement portée en justice à la suite du licenciement d'un chauffeur de cars sikh qui le portait. L'histoire a ainsi joué un rôle dans l'acceptation d'un signe ostentatoire. Ce n'est pas le cas en France, qui ne partage pas cette histoire, et où le turban est assimilé par la population à l'islam. On peut aussi rappeler que le Canada autorise les sikhs à porter le poignard traditionnel à la taille (dans une gaine protectrice qui empêche un usage violent). Anne-Laure Zwilling aborde la question de la recherche de visibilité chez les protestants évangéliques français. Une de leurs stratégies serait l'adhésion à la fédération protestante de France (FPF), où ils sont maintenant presque majoritaires. Ceux qui ne veulent pas rallier la FPF se regroupent dans le CNEF (Conseil National des Évangéliques de France), ce qui aboutit à avoir deux organismes représentatifs qui s'affirment chacun comme représentant légitime. L'adhésion à la FPF comme bouclier de protection face à la lutte antisecte française, qui a visé aussi les évangéliques a été évoquée par les chercheurs et par des membres de la FPF qui ne souhaitaient pas qu'on lui attribue ce rôle. Certains groupes évangéliques auraient demandé l'adhésion à la FPF pour partager avec elle le crédit de reconnaissance que lui accordent les autorités face à la délégitimisation qu'ils subissaient de la part des mouvements antisectes catholiques et rationalistes. L'aspect pratique de l'adhésion l'emporterait sur la recherche de visibilité. Une étude des étudiants thiantacounes sénégalais (J. F. Havard), qui sont des mourides, porte sur les modes de cette recherche de visibilité. Les intéressés sont apparemment peu soucieux d'être visibles en France. En revanche, ils tenteraient d'acquérir une visibilité ad intra grâce à un prosélytisme parmi les étudiants sénégalais en séjour en France. Cela passe par des réunions privées (thiant) religieuses et commensales, qui mobilisent la nostalgie du pays. Ils forment aussi une communauté par internet. Cette visibilité sur le Web aurait pu faire l'objet d'un chapitre car elle est l'une des stratégies utilisées par les catholiques traditionnalistes, opérant sur le Net à propos du mariage pour tous et de la gestation pour autrui, en multipliant les centres de diffusion afin d'avoir une couverture disproportionnée par rapport à leur nombre. Enfin, le commerce ethnique permet à Stéphane de Tapia d'évoquer la visibilité des minorités turques, chinoises et indiennes. Pour l'auteur, elle n'est pas uniforme, car elle dépend de l'histoire de l'immigration, de la composition des courants migratoires, du droit commercial local et des concurrences possibles entre les groupes ethniques ou leurs composantes. Mais, ici, nous sommes à la limite du cultuel et du culturel. Ce commerce ethnique est lié à des prescriptions religieuses, dans le cas de la viande hallal par exemple, mais il peut être uniquement profane et offrir des produits auxquels une catégorie d'émigrants est habituée. 